OPEN ACCESS

Edited by:

Raffaella Maria Gadaleta,

Inter University Consortium, Italy

Reviewed by:

Martha Robles-Flores,

National Autonomous University of

Mexico, Mexico

Vladimir Korinek,

Institute of Molecular Genetics

(ASCR), Czechia

Zhanfang Kang,

Qingyuan People's Hospital, China

*Correspondence:

Maria Sirakov

maria.sirakov@szn.it

Michelina Plateroti

plateroti@unistra.fr

Specialty section:

This article was submitted to Molecular and Structural

Endocrinology,

a section of the journal

Frontiers in Endocrinology

Received: 15 June 2021 Accepted: 16 November 2021 Published: 10 December 2021

Citation:

Sirakov $M$, Claret $L$ and Plateroti $M$ (2021) Thyroid Hormone Nuclear

Receptor TR $\alpha 1$ and Canonical WNT Pathway Cross-Regulation in Normal Intestine and Cancer.

Front. Endocrinol. 12:725708. doi: 10.3389/fendo.2021.725708

\section{Thyroid Hormone Nuclear} Receptor TR $\alpha 1$ and Canonical WNT Pathway Cross-Regulation in Normal Intestine and Cancer

\author{
Maria Sirakov $^{1 *}$, Leo Claret $^{2}$ and Michelina Plateroti ${ }^{2 *}$ \\ 1 Department of Biology and Evolution of Marine Organisms, Stazione Zoologica Anton Dohrn, Naples, Italy, ${ }^{2}$ Université de \\ Strasbourg, Inserm, Interface de Recherche fondamentale et Appliquée en Cancérologie (IRFAC)/Unité Mixte de Recherche \\ (UMR)-S1113, Fédération de Médecine Translationnelle de Strasbourg (FMTS), Strasbourg, France
}

A pivotal role of thyroid hormones and their nuclear receptors in intestinal development and homeostasis have been described, whereas their involvement in intestinal carcinogenesis is still controversial. In this perspective article we briefly summarize the recent advances in this field and present new data regarding their functional interaction with one of the most important signaling pathway, such as WNT, regulating intestinal development and carcinogenesis. These complex interactions unveil new concepts and will surely be of importance for translational research.

Keywords: thyroid hormones, thyroid hormone receptors, intestinal epithelium, intestinal carcinogenesis, canonical WNT pathway

\section{INTRODUCTION}

The role of the Thyroid Hormones (THs) in intestinal development have been established since the beginning of the $20^{\text {th }}$ century based on the observations on amphibian metamorphosis. Indeed, during this postnatal developmental process the gastrointestinal tract is dramatically remodeled, with a first phase of apoptosis followed by a strong increase of cell proliferation correlating with an increase of circulating THs (1).

\section{THE INTESTINAL EPITHELIUM}

The intestinal epithelium is a tissue which combines the absorptive properties of a single layered/ high-surface epithelium with the protective advantages of a constantly renewing barrier. It comprises six different mature cell types, which are separated into absorptive (enterocytes and $\mathrm{M}$ cells) and secretory (goblet, enteroendocrine, tuft and paneth cells) lineages. The different cell types allow functions such as the nutrient uptake, metabolic control and immune regulation. Thus, the intestinal epithelium is a multifunctional dynamic tissue highly dependent on continuous supply of all cell types in appropriate ratios (2). The epithelial lineages are derived from Intestinal Stem Cells (ISCs) which are located at or near the base of the intestinal crypts (3). The crypts are invagination of the intestinal wall, where the ISCs are well protected from the hazards of the digestive process occurring in the lumen. Within the crypts, self-renewing ISCs give rise to progenitor cells that 
rapidly proliferate and commit into epithelial lineages $(2,3)$. These cells are then pushed out of the crypts, they differentiate while migrating and die by apoptosis at the apex of the villi. This system efficiently secludes the ISCs and exposes to the hazards of the digestive tract only postmitotic cells that are programmed to die $(2,3)$. Paneth cells represent the exception to this rule, since they migrate downwards to the base of the crypts where they reside with a lifespan of approximately 30 days (2).

Homeodomain transcription factors (such as $C d x$ genes) and several pathways (including WNT, Hedgehog, Notch, BMP) play crucial roles in diverse developmental and homeostatic processes $(2,4)$. While the molecular basis of their action is well understood, the complex cross-regulation that occurs between them and/or with the environment (i.e. fibroblasts, myofibroblasts, immune cells, microbiota) still need to be better defined.

\section{FROM HOMEOSTASIS TO CANCER: THE CANONICAL WNT PATHWAY IN THE INTESTINE}

Among the signalling pathways mentioned in the previous paragraph, the WNT pathway is highly conserved and fundamental for intestinal development, cell proliferation and differentiation, ISCs maintenance. No other pathway plays such an important role on the self-renewal/proliferative capability and cell fate of ISCs $(2,5)$. Indeed, the Tcf7l2-knockout mice (the $T c f 7 l 2$ gene encodes for TCF4, the transcriptional activator of the canonical WNT signalling) show a strong impairment in epithelial renewal and the ISC compartment is entirely absent (6). Other two papers reported that blocking WNT pathway by the targeted overexpression of the WNT inhibitor Dickkopf-1 in the intestinal epithelium, induces in vivo the complete loss of the proliferative compartment $(7,8)$. On the other side, van de Wetering and colleagues concluded that the $\beta$-catenin/Tcf 4 transcriptional complex constitutes the master switch that controls proliferation versus differentiation in healthy and malignant intestinal epithelial cells (9). In the context of cancer, the WNT signalling pathway is well known for its role as a key driver of intestinal tumorigenesis. In fact, among the most frequently mutated genes, the very early event in cell transformation depends on the uncontrolled activation of the $\mathrm{WNT} / \beta$-catenin pathway. This is driven very frequently by lossof-function (LOF) mutations of the $A P C / A p c$ gene, whose product in a wild type (WT) context, blocks the functionality of the $\beta$-catenin and thus the activity of the pathway $(10,11)$. Other genes participating in this pathway frequently mutated in cancer include AXIN2/Axin2 (LOF) as well as CTNNB1/Ctnnb1 gain-of-function (GOF), the last encoding for the $\beta$-catenin protein. Specifically, CTNNB1/Ctnnb1 mutations are responsible for a stabilized oncogenic form of the protein (10, 11). It is important to underline that several signalling pathways can synergize with and induce WNT pathway activation to accelerate the early steps of tumorigenesis. Indeed, the Notch (12), Shh (13), Yap/Taz (14) are examples of signalling pathways which trigger APC-dependent tumorigenesis. Finally, we have demonstrated that THs via their Nuclear Receptor $\alpha 1$ (namely Thyroid hormone Receptor $\alpha 1, \mathrm{TR} \alpha 1$ ) can be included in this list $(15,16)$.

\section{TRs IN THE INTESTINAL DEVELOPMENT AND HOMEOSTASIS}

The action of THs in the nucleus depends on the ability of TRs to bind the hormone T3, which is then considered as the active hormone and the cellular effector of THs. TRs activate or repress the transcription of target genes by binding to specific DNA sequences called thyroid hormone response elements (TREs) (17). During the amphibian metamorphosis different TRs are distinctly involved. Indeed, the Thyroid hormone Receptor $\alpha$ (TR $\alpha$ ) is expressed at low level in the tadpole pre-metamorphic intestine whereas the Thyroid hormone Receptor $\beta(\operatorname{TR} \beta)$ is strongly increased after the surge in the TH level and they both play a fundamental role during the gut remodeling process (18). Moving to mammals, the generation of specific murine models helped to elucidate the function of THs in multiple organs and tissues including the intestinal epithelium (19). In mammals, the postnatal maturation consists of an increase in mucosal growth coupled to a burst in cell proliferation (19). Interestingly, THs level increases significantly in rodents at the weaning period (20), when the intestine undergoes this structural and functional reshaping. This increase has been also correlated with the mucosal growth and the onset of adult-type digestive enzymes expression in the enterocytes (21). Detailed analyses in murine models helped to define the different specific actions of TR $\alpha 1$ in intestinal epithelium progenitor/stem cell physiology. First, their proliferation strongly correlates with T3 levels and TR $\alpha 1$ expression $(21,22)$. Second, the activity of the ISCs at homeostasis and the regenerative properties of the epithelium after $\gamma$-ray irradiation are strongly affected by the lack of TR $\alpha 1$ expression $(23,24)$. Third, the targeted overexpression of TR $\alpha 1$ in the intestinal epithelium (vil-TR $\alpha 1$ mice) results in crypt hyperplasia and enhanced proliferation up to adenoma development (15).

\section{THs-TRs AND COLORECTAL CANCERS: STILL MORE WORK NEEDED}

Epidemiologic studies attempted to define a correlation between altered THs status in patients and cancer development (25). Generally speaking, there is still a lack of consensus since both a stimulating/blocking action of THs or mutated TRs have been described in several tumor types (25-28). Accordingly, hypothyroidism is a beneficial factor for ocular melanoma and mammary cancer (29) whereas it represents an aggravating risk in the case of hepatocarcinomas (26). Nevertheless, an increased risk for colon, lung, prostate, and breast cancer with increased THs has been demonstrated, even suggesting a TH-dose effect on cancer occurrence (30). The ambiguity from epidemiological studies on 
THs and colorectal cancer (CRC) may arise from important missing information on: (i) mutational status of oncogenes (APC, KRAS, TP53) when hypo- or hyper-thyroidism appears, (ii) combination of mutations and/or expression of key genes and/ or activation or repression of signalling pathways in different cell types influencing the biology of the cancer cells, (iii) local availability of the hormone (31) which is not directly correlated with the circulating levels of the THs but it is dependent on the levels of the TH-activating/inactivating enzymes and transporters (32). Indeed, the deiodinases selenoenzymes such as Dio2 (which converts T4 into T3), Dio3 (which converts T4 and T3 into revT3 and T2) appear important actors of THs activity (32). A complex interplay between Dio2 (i.e., high T3), Dio3 (i.e. low T3) and Shh (33) or WNT (34) has been described in skin tumors or in colon cancer, respectively. In this last case, Dio3 is upregulated by WNT signal resulting in a positive effect on cell proliferation (34) and, contrary to our observations in animals $(15,16,24)$, a report also indicates a negative effect of T3 on cancer stem cells maintenance in vitro (35). Concerning the TRs, it has been shown that their mutation or aberrant expression is associated with gastrointestinal tumors (25). In particular, $\operatorname{TR} \beta$ gene is frequently methylated and its expression strongly decreased in colon cancer (36) whereas it is still unclear whether in this same context TR $\alpha$ gene expression is altered.

More work is clearly needed. In particular, the studies reported above do not take into account the complexity and the heterogeneity of the tumors. Hypo- or hyper-thyroidism per se are probably not directly involved in inducing mutations, but stimulate or inhibit cellular processes that can facilitate tumor development in the presence of a favorable genetic background.

\section{TR $\alpha 1 /$ WNT CROSSTALK IN THE PHYSIO-PATHOLOGY OF THE INTESTINE}

TR $\alpha 1$ controls the proliferation of the mouse intestinal epithelium precursor cells by modulating, directly or indirectly, the expression of genes involved in cell cycle control, some of them being related to the WNT pathway $(20,37)$. For instance, $\mathrm{TR} \alpha 1$ is a direct transcriptional regulator of the Ctnnb1 gene. The increased expression of $\beta$-catenin, in turn, activates its targets such as cyclins D1 and D2 as well as $c-M y c$ which can be considered TR $\alpha 1$ indirect targets (20). Another TR $\alpha 1$ direct target in the intestinal epithelium is the secreted frizzled-related protein (Sfrp2), which is another component of the WNT pathway (38). Interestingly, through its regulation by $\mathrm{TR} \alpha 1$, we showed that sFRP2 stabilizes $\beta$-catenin in intestinal progenitors in vivo and in primary cells (39). These genes have been identified through a transcriptional analysis performed in cells isolated from the intestinal crypts of WT, $\mathrm{TR}^{0 / 0}$ and $\mathrm{TR} \beta^{-/-}$ mice (37). Moreover, the constitutive TR $\alpha 1$ overexpression in the intestinal epithelium (vil-TR $\alpha 1$ mice) not only confirmed their regulation but showed an increased cell proliferation and adenoma development even though it was not able per se to induce tumorigenesis (15). Interestingly, the $\operatorname{TR} \alpha 1$ overexpression enhanced the intestinal tumorigenic process in the $\mathrm{Apc}^{+/ 1638 \mathrm{~N}}$ (40) animals (vil-TR $\alpha 1 / \mathrm{Apc}^{+/ 1638 \mathrm{~N}}$ mice, hereafter designated as vil-TR $\alpha 1 / \mathrm{Apc}$ ) (15) while TR $\alpha$-KO in the same Apc-mutated background retarded tumor development (16). One of the most interesting molecular features of the vilTR $\alpha 1 / A p c$ mice is the increased activity of the WNT pathway compared with that of the Apc-simple mutants, which is likely responsible of the earlier onset of tumor development in the vilTR $\alpha 1 / A p c$ mice (15). Importantly, looking for the mechanisms involved, we characterized the molecular signature of TR $\alpha 1$ expressing murine tumors that includes Wnt and Notch pathways as well as stem cell markers (16). We also demonstrated in cohorts of CRC patients a significant upregulation of $T R \alpha 1$ and a positive highly significant correlation between TR $\alpha 1$ expression and WNT pathway activity, therefore validating the relevance of the fundamental observations in clinics (16). Finally, the modulation of TR $\alpha 1$ expression in human colon adenocarcinoma cell lines, directly correlated with proliferation, migration and WNT pathway activity (41).

In order to further investigate and shed more light in this cross-talk we performed cellular and molecular analyses in animals as well as in cells (methodological details in Supplementary Materials and Methods). As shown in Figure 1, the mRNA expression of WNT targets such as Ccnd1 and $c-M y c$ (Figure 1A) is up-regulated in vil-TR $\alpha 1$ intestines compared to the WT and their level is similar to the normal part of the vil-TR $\alpha 1 / A p c$ double mutant mice. However, in the lesions of these animals there is a further up-regulation, probably due to the WNT pathway hyperactivation in the context of the synergistic TR $\alpha 1$ overexpression and Apc mutation $(15,16)$. The mRNAs encoding for the WNT transcriptional effectors $T c f 7 l 2$ and Lef1 present an expression pattern similar to those of their molecular targets (Figure 1A). The expression of TR $\alpha 1$ direct targets Ctnnb1 and Sfrp2 behave in different manner and, surprisingly, their expression is diminished in the double mutant intestines (normal or lesions) compared to the simple vil-TR $\alpha 1$ mice (Figure 1B). TR $\alpha 1$ and $\beta$-catenin/Tcf4 bind to specific genomic sequences called TRE and WNT Responsive Elements (WRE), respectively. We decided to analyze the reciprocal influence of TR $\alpha 1, \beta$-catenin and Tcf4 in a cellular test in vitro using the respective luciferasedriven reporters DR4/TRE (20) and TopFlash/WRE (42). For this aim, we transfected $\mathrm{Caco} 2$ cells with the specific reporters and observed that the DR4-luciferase activity dependent on TR $\alpha 1$ can be impaired by the co-transfection of $\beta$-catenin and Tcf4 (Figure 1C). On the contrary, TR $\alpha 1$ transfection had a small but significant positive effect on the TopFlash-driven luciferase response (Figure 1C). All these experiments were conducted in cells in the presence of serum, thus containing physiological concentrations of THs (43). FopFlash and mutDR4 have been used as negative control and, as expected, we could not detect any modulation of the luciferase activity (data not shown). Intriguingly, the luciferase response was also present in the absence of T3 (our unpublished observation), indicating that TR $\alpha 1$ functionally interacts with the $\beta$-catenin/Tcf 4 

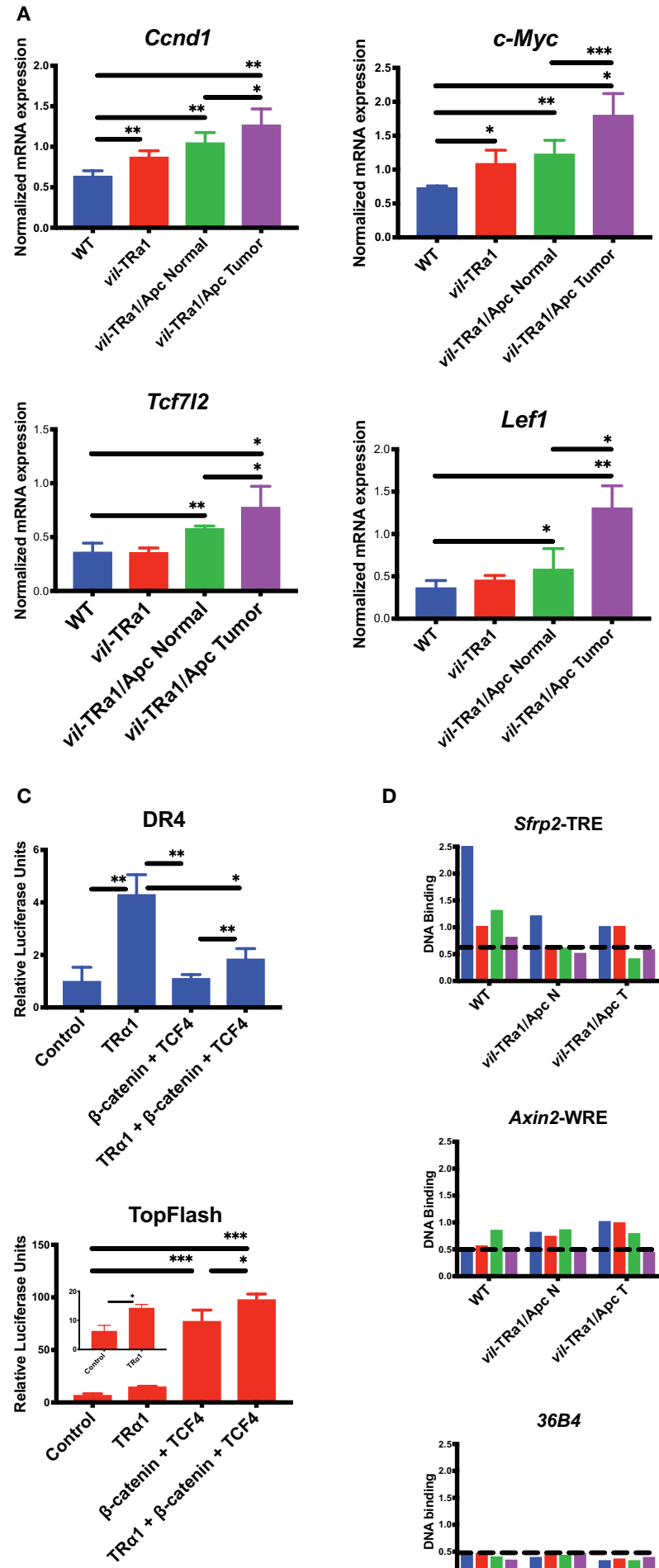

D

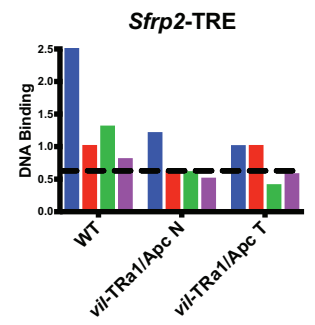

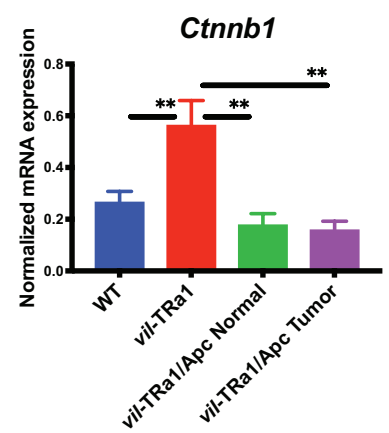
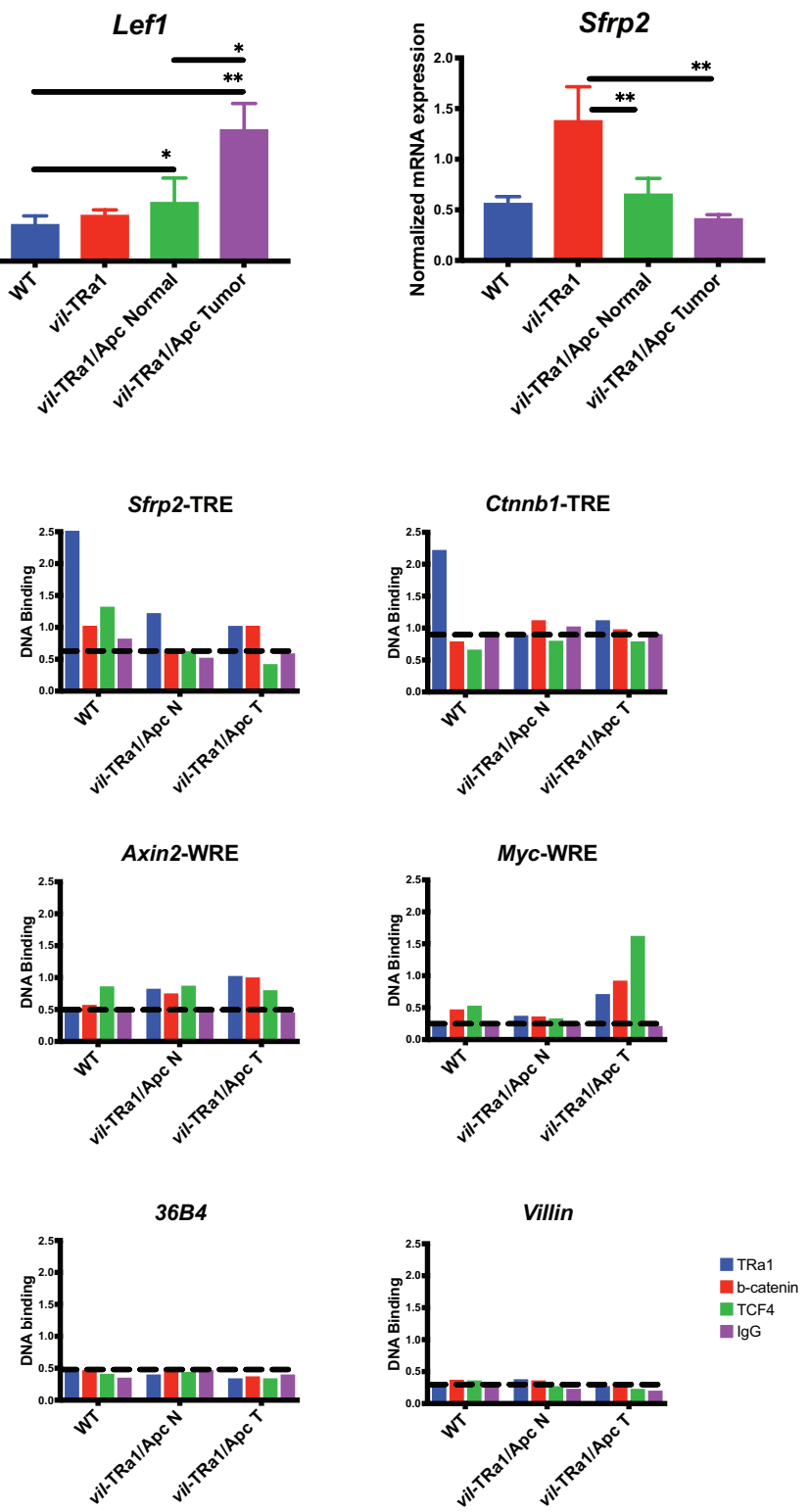

FIGURE 1 | Continued 
FIGURE 1 | Functional interaction between TR $\alpha 1$ and $\beta$-catenin/Tcf4 complex. (A, B) Gene expression analysis was performed in the intestine or tumors from 1-month (young) or 6-month-old mice of the indicated genotype. Specifically, Ccnd1 and c-Myc Wnt targets and, Tcf7l2 and Lef1 Wnt transcriptional effectors (A) or the TR 1 1 direct targets Ctnnb1 and Sfrp2 (B) were analyzed. Values represent fold change \pm sd, after normalization with $P$ pib. ${ }^{*} \mathrm{P}<0.05$, ${ }^{* \star} \mathrm{P}<0.01$, ${ }^{\star \star *} \mathrm{P}<0.001 \mathrm{compared}$ to indicated conditions, by unpaired two-tailed Student's t-test $(n=4)$. (C) A synthetic DR4-driving luciferase reporter (TR $\alpha 1$ response) or the TopFlash luciferase reporter (Wnt response) were transfected into Caco2 cells maintained in culture medium containing physiological concentrations of T3, together with TR $\alpha 1$, Tcf4 or $\beta$-catenin expression vectors in different combinations, as indicated. Histograms represent mean $\pm \mathrm{sd}$. ${ }^{\star} \mathrm{P}<0.05,{ }^{\star \star} \mathrm{P}<0.01,{ }^{\star \star \star} \mathrm{P}<0.001$, compared to indicated conditions, by unpaired two-tailed Student's t-test ( $n=9$ ). (D) ChIP analysis was performed on chromatin isolated from the intestine of WT or vil-TR $\alpha 1 / A p c$ mice normal intestine (N) or tumors (T). DNA/protein complexes were precipitated with anti-TR $\alpha 1$, anti- $\beta$-catenin, anti-Tcf4 antibodies or rabbit lgG (negative control). qPCR was performed on purified DNA from each condition by using specific primers covering the TRE of Sfrp2 and Ctnnb1, the WRE of Axin2 and c-Myc or the promoters of Villin and $36 B 4$ as indicated; the Ppia gene was used as internal control. Histograms represent the specific-DNA enrichment in each sample precipitated with the indicated antibody. The horizontal black dotted bars in each panel delineates the threshold of binding specificity determined by the lgG non-specific binding.

complex independently from the hormone. These results in cells pushed us to investigate the eventual presence of the three proteins on the chromatin, by using an in vivo chromatin immunoprecipitation (ChIP) approach to analyze the TREs and WREs of the specific target genes of TR $\alpha 1$ and $\beta$-catenin/ Tcf4, respectively. As shown in Figure 1D, in the WT intestine, TR $\alpha 1$ binds to the promoter region of the Sfrp 2 and Ctnnb1 genes containing TRE elements (37). As the Sfrp 2 and Ctnnb1 expression profiles suggested, the TR $\alpha 1$ chromatin occupancy changed between the WT and mutant intestine. In fact, in vilTR $\alpha 1 / A p c$ mice, the TR $\alpha 1$-specific DNA binding on the regulatory regions is lost, when compared with the WT animals. To analyze the specific DNA binding of $\beta$-catenin/ Tcf4 on their target genes and the eventual presence of TR $\alpha 1$ in the same regions, we decided to look at WREs described within the Axin2 (44) and $c-M y c$ (45), two classical direct WNT targets. In both cases (Figure 1D) TR $\alpha 1$ was not present on the WRE regions in the WT intestine but was clearly enriched on them, both in normal mucosae and the tumors of vil-TR $\alpha 1 /$ Apc mice (Figure 1D). As we could not find any TREs within the Axin2 or $c-M y c$ genomic regions in proximity of the WREs analyzed, we speculate that TR $\alpha 1$ might be present as a protein partner to
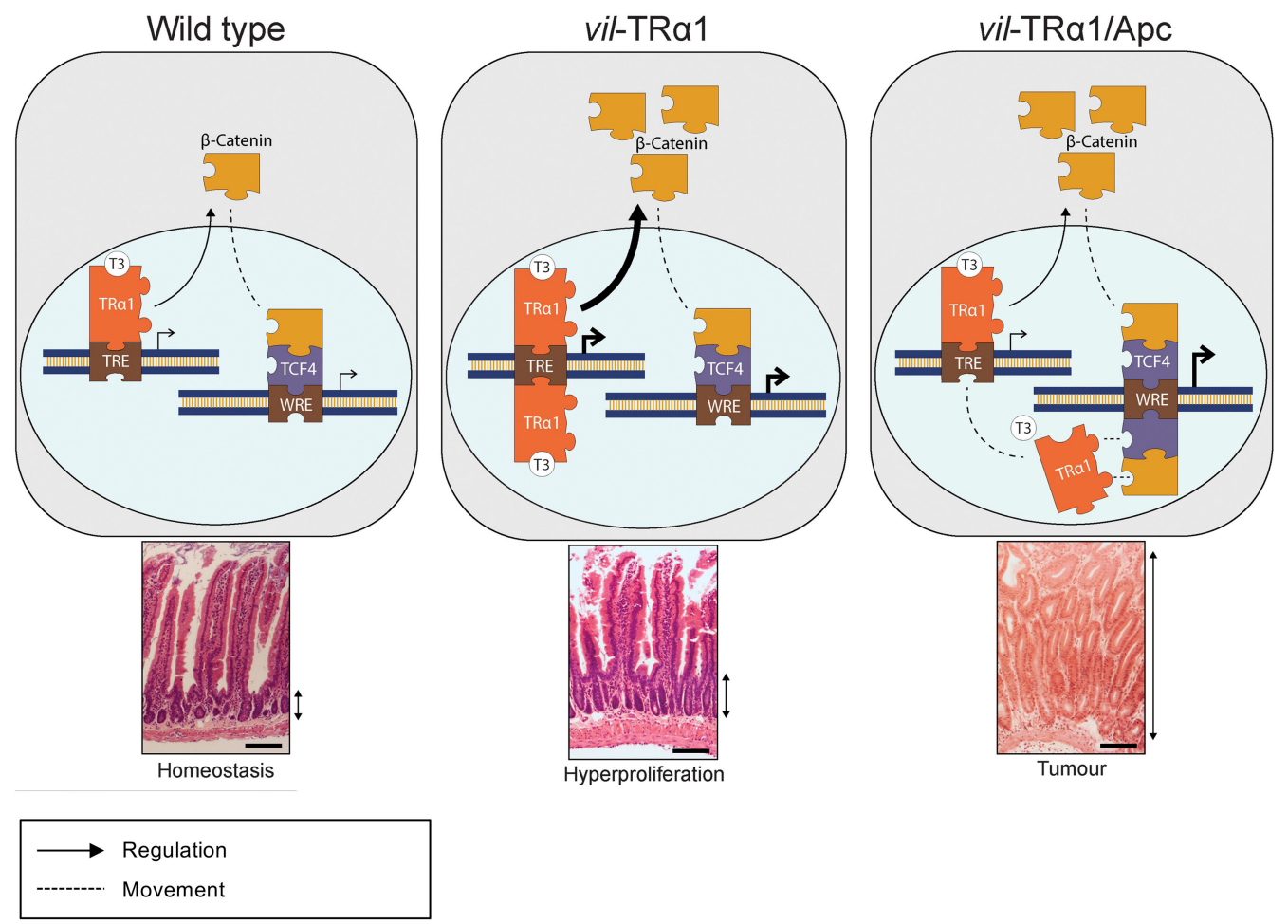

FIGURE 2 | Proposed cross-regulation of TR $\alpha 1$ and Wnt effectors in normal intestine and in tumors. In physiological conditions (Wild Type panel), TR $\alpha 1$ binding on TREs regulates in a positive manner the expression and stabilization of $\beta$-catenin, then contributing to maintain epithelial homeostasis. In vil-TR $\alpha 1$ mice, the levels of stabilized $\beta$-catenin are increased leading to WNT activation and hyper-proliferation. In vil-TR $\alpha 1 /$ Apc mice, the stronger $\beta$-catenin stabilization and Tcf4 overexpression might induce a competitive shift in TR $\alpha 1$ binding from TREs to WREs. We can speculate that this mechanism is one of the factors responsible for the activation and/or the acceleration of the tumorigenic process dependent upon TR $\alpha 1$-up regulation. TREs, Thyroid hormone response elements; WREs, WNT response elements. Solid arrows indicate genomic actions; dotted lines represent (i) the $\beta$-catenin translocation from cytoplasm to nucleus and (ii) the speculative model of TR $\alpha 1$ shift from TRE to WRE. Thickness of the solid arrows indicates an increased level of transcriptional activity. Double black arrows indicate crypt width in WT and vil-TR $\alpha 1$ intestinal sections or the size of the altered mucosa in vil-TR $\alpha 1 /$ Apc tumor. 
amplify the transcriptional response dependent upon the WNT effectors $\beta$-catenin/Tcf4.

\section{DISCUSSION AND CONCLUSIONS}

Complex cross-talks between signaling pathways and hormones, such as T3, have been described in several physiological models and in cancers $(41,46,47)$. We reported here recent literature and also included new data on the intriguing relations between THs/TR $\alpha 1$ and $W N T / \beta$-catenin pathway in normal intestine and in tumors. From these different findings we propose the model summarized in Figure 2. Indeed, in a normal intestine TR $\alpha 1$ and the WNT effectors control their own target genes (Wild Type panel). When TR $\alpha 1$ is up-regulated in a normal context (vil-TR $\alpha 1$ mice) it stimulates its target genes including $\beta$ catenin, resulting in the activation of the WNT pathway and, by consequence, increased crypt proliferation, through the mechanisms we have already described $(41,48)$. In the case of the tumors (panel vil-TR $\alpha 1 / \mathrm{Apc}$ ), the stronger increase of the $\beta$ catenin/Tcf4 complex not only induces the WNT pathway activity but may also act to "displace" TR $\alpha 1$ from its own targets to the WNT targets. We may speculate that the "displacement" of TR $\alpha 1$ can be considered the molecular counterpart of the WNT hyperactivation resulting from the interaction of this two signalling pathways. Indeed, in the intestinal tumors of vil-TR $\alpha 1 /$ Apc mice the transcriptional activity of TR $\alpha 1$ on its own target is similar to that observed in WT condition, despite the nuclear receptor is expressed at augmented levels comparable with those of vil-TR $\alpha 1 /$ Apc mice. It is worth noting that $\operatorname{TR} \beta$ or other nuclear receptors and $\beta$ catenin/Tcf (alone or in combination) have been shown to form protein complexes (49-52). We can speculate that TR $\alpha 1$ interacts with $\beta$-catenin/Tcf4 complex on WNT targets and that this process might be independent from T3. In addition, this interaction could contribute to the WNT pathway hyperactivation. In the case of the normal mucosae of vil-TR $\alpha 1 / \mathrm{Apc}$ mice, the molecular phenotype is even more intriguing, given that these portions of the intestines have histological appearance similar to that of the vil-TR $\alpha 1$, but show molecular features close to the tumors.

According to the literature and also considering our work, THs-TRs definitively play a pivotal role in intestinal development and homeostasis in both mouse and amphibians by regulating the expression of a large panel of genes, including those belonging to the WNT pathway and cell cycle regulators $(37,53,54)$. It is important to underline that all these studies provide data that can be now used in bioinformatics and statistics analyses for a direct comparison of TH-TR dependent

\section{REFERENCES}

1. Brown DD, Cai L. Amphibian Metamorphosis. Dev Biol (2007) 306:20-33. doi: 10.1016/j.ydbio.2007.03.021

2. Gehart H, Clevers H. Tales From the Crypt: New Insights Into Intestinal Stem Cells. Nat Rev Gastroenterol Hepatol (2019) 16:19-34. doi: 10.1038/s41575018-0081-y mechanisms in the intestine of different species. Such a study will aim to identify common/uncommon mechanisms, genes directly or indirectly regulated in developmental, homeostatic and pathological conditions. This comparative analysis will surely be of importance for translational research. Indeed, when considering the tumor heterogeneity and cell plasticity within the CRCs (55-57), one of the future challenges will be to fully define the genes and signalling networks influencing the activity of TR $\alpha 1$ and, vice-versa, the cascade of regulations depending on THs-TR $\alpha 1$.

\section{DATA AVAILABILITY STATEMENT}

The original contributions presented in the study are included in the article/Supplementary Material. Further inquiries can be directed to the corresponding authors.

\section{ETHICS STATEMENT}

The animal study was reviewed and approved by Ministère de l'Enseignement Supérieur et de la Recherche, Direction Générale pour la Recherche et l'Innovation, Secrétariat “Autorisation de projet" (agreement \#02847.01).

\section{AUTHOR CONTRIBUTIONS}

MS participated in the design of the study, performed all the experiment, carried out the data analysis and drafted the manuscript. LC helped in design the manuscript, figure preparation and revised the manuscript. MP conceived and supervised the study, carried out the data analysis drafted and revised the manuscript. All authors contributed to the article and approved the submitted version.

\section{FUNDING}

MP lab is supported by the FRM (Equipes FRM 2018, DEQ20181039598), by the Inca (PLBIO19-289) and by the Ligue Contre le Cancer, Département Grand Est (01X.2020). LC received support from the FRM.

\section{SUPPLEMENTARY MATERIAL}

The Supplementary Material for this article can be found online at: https:/www.frontiersin.org/articles/10.3389/fendo.2021.725708/ full\#supplementary-material

3. Sailaja BS, He XC, Li L. The Regulatory Niche of Intestinal Stem Cells. J Physiol (2016) 594:4827-36. doi: 10.1113/JP271931

4. Hryniuk A, Grainger S, Savory JGA, Lohnes D. Cdx Function Is Required for Maintenance of Intestinal Identity in the Adult. Dev Biol (2012) 363:426-37. doi: 10.1016/j.ydbio.2012.01.010

5. Perochon J, Carroll LR, Cordero JB. Wnt Signalling in Intestinal Stem Cells: Lessons From Mice and Flies. Genes (Basel) (2018) 9:1-19. doi: 10.3390/genes9030138 
6. Korinek V, Barker N, Moerer P, Van Donselaar E, Huls G, Peters PJ, et al. Depletion of Epithelial Stem-Cell Compartments in the Small Intestine of Mice Lacking Tcf-4. Nat Genet (1998) 19:379-83. doi: 10.1038/1270

7. Kuhnert F, Davis CR, Wang HT, Chu P, Lee M, Yuan J, et al. Essential Requirement for Wnt Signaling in Proliferation of Adult Small Intestine and Colon Revealed by Adenoviral Expression of Dickkopf-1. Proc Natl Acad Sci USA (2004) 101:266-71. doi: 10.1073/pnas.2536800100

8. Pinto D, Gregorieff A, Begthel H, Clevers H. Canonical Wnt Signals Are Essential for Homeostasis of the Intestinal Epithelium. Genes Dev (2003) 17:1709-13. doi: $10.1101 /$ gad.267103

9. Van de Wetering M, Sancho E, Verweij C, De Lau W, Oving I, Hurlstone A, et al. The $\beta$-Catenin/TCF-4 Complex Imposes a Crypt Progenitor Phenotype on Colorectal Cancer Cells. Cell (2002) 111:241-50. doi: 10.1016/S0092-8674(02)01014-0

10. Ichii S, Horii A, Nakatsuru S, Furuyama J, Utsunomiya J, Nakamura Y. Inactivation of Both APC Alleles in an Early Stage of Colon Adenomas in a Patient With Familial Adenomatous Polyposis (FAP). Hum Mol Genet (1992) 1:387-90. doi: $10.1093 / \mathrm{hmg} / 1.6 .387$

11. Levy DB, Smith KJ, Beazer-Barclay Y, Hamilton SR, Vogelstein B, Kinzler KW. Inactivation of Both APC Alleles in Human and Mouse Tumors. Cancer Res (1994) 54:5953-8.

12. Fre S, Pallavi SK, Huyghe M, Laé M, Janssen KP, Robine S, et al. Notch and Wnt Signals Cooperatively Control Cell Proliferation and Tumorigenesis in the Intestine. Proc Natl Acad Sci USA (2009) 106:6309-14. doi: 10.1073/ pnas.0900427106

13. Taipale J, Beachy PA. The Hedgehog and Wnt Signalling. Nature (2001) 411:349-54. doi: 10.1038/35077219

14. Deng F, Peng L, Li Z, Tan G, Liang E, Chen S, et al. YAP Triggers the Wnt/ $\beta$ Catenin Signalling Pathway and Promotes Enterocyte Self-Renewal, Regeneration and Tumorigenesis After DSS-Induced Injury. Cell Death Dis (2018) 9(2):153. doi: 10.1038/s41419-017-0244-8

15. Kress E, Skah S, Sirakov M, Nadjar J, Gadot N, Scoazec JY, et al. Cooperation Between the Thyroid Hormone Receptor Trol and the WNT Pathway in the Induction of Intestinal Tumorigenesis. Gastroenterology (2010) 138:186374.e1. doi: 10.1053/j.gastro.2010.01.041

16. Uchuya-Castillo J, Aznar N, Frau C, Martinez P, Le Nevé C, Marisa L, et al. Increased Expression of the Thyroid Hormone Nuclear Receptor TRa1 Characterizes Intestinal Tumors With High Wnt Activity. Oncotarget (2018) 9:30979-96. doi: 10.18632/oncotarget.25741

17. Yen PM, Ando S, Feng X, Liu Y, Maruvada P, Xia X. Thyroid Hormone Action at the Cellular, Genomic and Target Gene Levels. Mol Cell Endocrinol (2006) 246:121-7. doi: 10.1016/j.mce.2005.11.030

18. Ishizuya-Oka A, Shi YB. Molecular Mechanisms for Thyroid HormoneInduced Remodeling in the Amphibian Digestive Tract: A Model for Studying Organ Regeneration. Dev Growth Differ (2005) 47:601-7. doi: 10.1111/j.1440-169X.2005.00833.x

19. Sirakov M, Plateroti M. The Thyroid Hormones and Their Nuclear Receptors in the Gut: From Developmental Biology to Cancer. Biochim Biophys Acta Mol Basis Dis (2011) 1812:938-46. doi: 10.1016/j.bbadis.2010.12.020

20. Plateroti M, Kress E, Mori JI, Samarut J. Thyroid Hormone Receptor $\alpha 1$ Directly Controls Transcription of the $\beta$-Catenin Gene in Intestinal Epithelial Cells. Mol Cell Biol (2006) 26:3204-14. doi: 10.1128/mcb.26.8.3204-3214.2006

21. Plateroti M, Chassande O, Fraichard A, Gauthier K, Freund JN, Samarut J, et al. Involvement of T3R $\alpha$ - and $\beta$-Receptor Subtypes in Mediation of T3 Functions During Postnatal Murine Intestinal Development. Gastroenterology (1999) 116:1376-8. doi: 10.1016/S0016-5085(99)70501-9

22. Bao L, Roediger J, Park S, Fu L, Shi B, Cheng SY, et al. Thyroid Hormone Receptor Alpha Mutations Lead to Epithelial Defects in the Adult Intestine in a Mouse Model of Resistance to Thyroid Hormone. Thyroid (2019) 29:43948. doi: 10.1089/thy.2018.0340

23. Kress E, Rezza A, Nadjar J, Samarut J, Plateroti M. The Thyroid Hormone Receptor- $\alpha(\operatorname{Tr} \alpha)$ Gene Encoding Tr $\alpha 1$ Controls Deoxyribonucleic Acid Damage-Induced Tissue Repair. Mol Endocrinol (2008) 22:47-55. doi: 10.1210/me.2007-0278

24. Godart M, Frau C, Farhat D, Giolito MV, Jamard C, Le Nevé C, et al. The Murine Intestinal Stem Cells Are Highly Sensitive to the Modulation of the T3/Tra1-Dependent Pathway. Development (2021) 148(8):dev194357. doi: 10.1242/dev.194357
25. Krashin E, Piekiełko-Witkowska A, Ellis M, Ashur-Fabian O. Thyroid Hormones and Cancer: A Comprehensive Review of Preclinical and Clinical Studies. Front Endocrinol (Lausanne) (2019) 10:59. doi: 10.3389/ fendo.2019.00059

26. Perra A, Plateroti M, Columbano A. T3/TRs Axis in Hepatocellular Carcinoma: New Concepts for an Old Pair. Endocr Relat Cancer (2016) 23: R353-69. doi: 10.1530/ERC-16-0152

27. Hörkkö TT, Tuppurainen K, George SM, Jernvall P, Karttunen TJ, Mäkinen MJ. Thyroid Hormone Receptor $\beta 1$ in Normal Colon and Colorectal Cancer - Association With Differentiation, Polypoid Growth Type and K-Ras Mutations. Int J Cancer (2006) 118:1653-9. doi: 10.1002/ ijc. 21556

28. Brown AR, Simmen RCM, Simmen FA. The Role of Thyroid Hormone Signaling in the Prevention of Digestive System Cancers. Int J Mol Sci (2013) 14(8):16240-57. doi: 10.3390/ijms140816240

29. Cristofanilli M, Yamamura Y, Kau SW, Bevers T, Strom S, Patangan M, et al. Thyroid Hormone and Breast Carcinoma: Primary Hypothyroidism Is Associated With a Reduced Incidence of Primary Breast Carcinoma. Cancer (2005) 103:1122-8. doi: 10.1002/cncr.20881

30. Moeller LC, Führer D. Thyroid Hormone, Thyroid Hormone Receptors, and Cancer: A Clinical Perspective. Endocr Relat Cancer (2013) 20(2):R19-29. doi: 10.1530/ERC-12-0219

31. Boelen A, Kwakkel J, Fliers E. Beyond Low Plasma T 3: Local Thyroid Hormone Metabolism During Inflammation and Infection. Endocr Rev (2011) 32:670-93. doi: 10.1210/er.2011-0007

32. Bianco AC, Kim BW. Deiodinases: Implications of the Local Control of Thyroid Hormone Action. J Clin Invest (2006) 116(10):2571-9. doi: 10.1172/ JCI29812

33. Dentice M, Luongo C, Huang S, Ambrosio R, Elefante A, Mirebeau-prunier D, et al. Sonic Hedgehog-Induced Type 3 Deiodinase Blocks Thyroid Hormone Action Enhancing Proliferation of Normal and Malignant Keratinocytes. Proc Natl Acad Sci USA (2007) 104:14466-71. doi: 10.1073/pnas.0706754104

34. Dentice M, Luongo C, Ambrosio R, Sibilio A, Casillo A, Iaccarino A, et al. $\beta$-Catenin Regulates Deiodinase Levels and Thyroid Hormone Signaling in Colon Cancer Cells. Gastroenterology (2012) 143:1037-47. doi: 10.1053/ j.gastro.2012.06.042

35. Catalano V, Dentice M, Ambrosio R, Luongo C, Carollo R, Benfante A, et al. Activated Thyroid Hormone Promotes Differentiation and Chemotherapeutic Sensitization of Colorectal Cancer Stem Cells by Regulating Wnt and BMP4 Signaling. Cancer Res (2016) 76:1237-44. doi: 10.1158/0008-5472.CAN-151542

36. Markowitz S, Haut M, Stellato T, Gerbic C, Molkentin K. Rapid Publication Expression of the ErbA-F3 Class of Thyroid Hormone Receptors Is Selectively Lost in Human Colon Carcinoma. J Clin Invest (1989) 84(5):1683-7. doi: 10.1172/JCI114349

37. Kress E, Rezza A, Nadjar J, Samarut J, Plateroti M. The Frizzled-Related Sfrp2 Gene is a Target of Thyroid Hormone Receptor $\alpha 1$ and Activates $\beta$-Catenin Signaling in Mouse Intestine. J Biol Chem (2009) 284:1234-41. doi: 10.1074/ jbc.M806548200

38. Bovolenta P, Esteve P, Ruiz JM, Cisneros E, Lopez-Rios J. Beyond Wnt Inhibition: New Functions of Secreted Frizzled-Related Proteins in Development and Disease. J Cell Sci (2008) 121:737-46. doi: 10.1242/ jcs.026096

39. Skah S, Nadjar J, Sirakov M, Plateroti M. The Secreted Frizzled-Related Protein 2 Modulates Cell Fate and the Wnt Pathway in the Murine Intestinal Epithelium. Exp Cell Res (2015) 330:56-65. doi: 10.1016/j.yexcr.2014.10.014

40. Fodde R, Edelmann W, Yang K, Van Leeuwen C, Carlson C, Renault B, et al. A Targeted Chain-Termination Mutation in the Mouse Apc Gene Results in Multiple Intestinal Tumors. Proc Natl Acad Sci USA (1994) 91:8969-73. doi: 10.1073/pnas.91.19.8969

41. Skah S, Uchuya-Castillo J, Sirakov M, Plateroti M. The Thyroid Hormone Nuclear Receptors and the Wnt/ $\beta$-Catenin Pathway: An Intriguing Liaison. Dev Biol (2017) 422:71-82. doi: 10.1016/j.ydbio.2017.01.003

42. Van de Wetering M, Cavallo R, Dooijes D, Van Beest M, Van Es J, Loureiro J, et al. Armadillo Coactivates Transcription Driven by the Product of the Drosophila Segment Polarity Gene dTCF. Cell (1997) 88:789-99. doi: 10.1016/ S0092-8674(00)81925-X 
43. Samuels HH, Stanley F, C J. Depletion of L-3,5,39-Triiodothyronine and LThyroxine in Euthyroid Calf Serum for Use in Cell Culture Studies of the Action of Thyroid Hormone. Endocrinology (1979) 105:80-5. doi: 10.1210/ endo-105-1-80

44. Mahmoudi T, Boj SF, Hatzis P, Li VSW, Taouatas N, Vries RGJ, et al. The Leukemia-Associated Mllt10/Af10-Dot1l Are Tcf4/ß-Catenin Coactivators Essential for Intestinal Homeostasis. PloS Biol (2010) 8(11):e1000539. doi: 10.1371/journal.pbio.1000539

45. Hu MC, Rosenblum ND. Smad1, $\beta$-Catenin and Tcf4 Associate in a Molecular Complex With the Myc Promoter in Dysplastic Renal Tissue and Cooperate to Control Myc Transcription. Development (2005) 132:215-25. doi: 10.1242/ dev.01573

46. Garg D, Ng SSM, Baig KM, Driggers P, Segars J. Progesterone-Mediated NonClassical Signaling. Trends Endocrinol Metab (2017) 28:656-68. doi: 10.1016/ j.tem.2017.05.006

47. Ni F-D, Hao S-L, Yang W-X. Molecular Insights Into Hormone Regulation via Signaling Pathways in Sertoli Cells: With Discussion on Infertility and Testicular Tumor. Gene (2020) 753:144812. doi: 10.1016/ j.gene.2020.144812

48. Sirakov M, Kress E, Nadjar J, Plateroti M. Thyroid Hormones and Their Nuclear Receptors: New Players in Intestinal Epithelium Stem Cell Biology? Cell Mol Life Sci (2014) 71:2897-907. doi: 10.1007/s00018-014-1586-3

49. Pakula H, Xiang D, Li Z. A Tale of Two Signals: AR and WNT in Development and Tumorigenesis of Prostate and Mammary Gland. Cancers (Basel) (2017) 9:1-34. doi: 10.3390/cancers9020014

50. Cao J, Ma Y, Yao W, Zhang X, Wu D. Retinoids Regulate Adipogenesis Involving the Tgf $\beta / S M A D$ and $W n t / \beta$-Catenin Pathways in Human Bone Marrow Mesenchymal Stem Cells. Int J Mol Sci (2017) 18(4):842. doi: 10.3390/ ijms18040842

51. Reinhold S, Blankesteijn WM, Foulquier S. The Interplay of WNT and Ppar $\gamma$ Signaling in Vascular Calcification. Cells (2020) 9:1-27. doi: 10.3390/ cells 9122658

52. Muralidhar S, Filia A, Nsengimana J, Pozniak J, O'Shea SJ, Diaz JM, et al. Vitamin D-VDR Signaling Inhibits Wnt/b-Catenin-Mediated Melanoma Progression and Promotes Antitumor Immunity. Cancer Res (2019) 79:5986-98. doi: 10.1158/0008-5472.CAN-18-3927
53. Hasebe T, Fujimoto K, Kajita M, Ishizuya-Oka A. Thyroid Hormone Activates Wnt/ $\beta$-Catenin Signaling Involved in Adult Epithelial Development During Intestinal Remodeling in Xenopus Laevis. Cell Tissue Res (2016) 365:309-18. doi: 10.1007/s00441-016-2396-8

54. Shibata Y, Tanizaki Y, Zhang H, Lee H, Dasso M, Shi Y-B. Thyroid Hormone Receptor Is Essential for Larval Epithelial Apoptosis and Adult Epithelial Stem Cell Development But Not Adult Intestinal Morphogenesis During Xenopus Tropicalis Metamorphosis. Cells (2021) 11(9):1368. doi: 10.3390/ cells10030536

55. Teeuwssen M, Fodde R. Cell Heterogeneity and Phenotypic Plasticity in Metastasis Formation: The Case of Colon Cancer. Cancers (Basel) (2019) 11 (9):1368. doi: 10.3390/cancers11091368

56. Zeuner A, Todaro M, Stassi G, De Maria R. Colorectal Cancer Stem Cells: From the Crypt to the Clinic. Cell Stem Cell (2014) 15:692-705. doi: 10.1016/ j.stem.2014.11.012

57. Hirata A, Hatano Y, Niwa M, Hara A, T H. Heterogeneity of Colon Cancer Stem Cells. In: Birbrair A, editor. Stem Cells Heterogeneity in Cancer. Advances in Experimental Medicine and Biology. Cham: Springer. p. 1139:115-26. doi: 10.1007/978-3-030-14366-4_7

Conflict of Interest: The authors declare that the research was conducted in the absence of any commercial or financial relationships that could be construed as a potential conflict of interest.

Publisher's Note: All claims expressed in this article are solely those of the authors and do not necessarily represent those of their affiliated organizations, or those of the publisher, the editors and the reviewers. Any product that may be evaluated in this article, or claim that may be made by its manufacturer, is not guaranteed or endorsed by the publisher.

Copyright (c) 2021 Sirakov, Claret and Plateroti. This is an open-access article distributed under the terms of the Creative Commons Attribution License (CC BY). The use, distribution or reproduction in other forums is permitted, provided the original author(s) and the copyright owner(s) are credited and that the original publication in this journal is cited, in accordance with accepted academic practice. No use, distribution or reproduction is permitted which does not comply with these terms. 